nhà. Tạp chí nghiên cứu Y học, 113 (4).

6. Forum on Aging D., Policy B. on H.S., Education D. on B. and S.S. and và cộng sự. (2015), Home Health Care: Today and Tomorrow, National Academies Press (US).
7. Nguyễn Thị Dung, Phạm Văn Dịu và cộng sự (2019). Sư sắn sàng và khả năng chi trả cho dich vư chẩn đoán bệnh từ xa (telemedicine) của người dần tỉnh Thái Bình năm 2018 và một sô yếu tố liên quan. Tạp chí nghiên cứu y học, 123 (7).

\title{
CĂNG THẲNG NGHỀ NGHIỆP CỦA NHÂN VIÊN Y TẾ TẠI BỆNH VIỆN TỈNH XIÊNG - KHOẢNG, LÀO, NĂM 2020
}

\section{TÓM TẮT}

Mục tiêu: Mô tả thực trạng căng thẳng nghề nghiệp của bác sĩ và điều dưỡng tại Bệnh viện tỉnh Xiêng-Khoảng, Lào, năm 2020. Phương pháp: nghiên cứu cắt ngang. Kết quả: Theo mô hình Karasek, những người tham gia nghiên cứu làm công việc chư động chiếm tỷ lệ cao nhất với $51,6 \%$, tiếp đển là nhóm làm công việc thoải mái chiếm $26,7 \%$, nhóm cảm nhận công việc của họ căng thẳng (áp lực tâm lý cao và quyên quyết định thấp) chiếm $14,3 \%$ và nhóm đối tượng nghiên cứu phải làm công việc thụ động chiếm tỷ lệ thấp nhất với 7,5\%. Kết luận: Tỷ lệ cẳng thẳng nghề nghiệp ở nhân viên y tế là $14,3 \%$. Với tỷ lệ căng thẳng trền thì điều cần thiết lúc này là Ban lãnh đạo bệnh viện cần có những biện pháp can thiêp thích hợp để góp phần cải thiện sức khỏe tâm thần cho nhân viên y tế.

Từ khóa: Căng thẳng nghề nghiệp, JCQ-V

Danh mục viết tắt: NVYT - Nhẩn viên y tế

\section{SUMMARY}

\section{OCCUPATIONAL STRESS OF MEDICAL STAFF AT XIENG - KHOANG PROVINCE HOSPITAL, LAOS, IN 2020}

Objective: Describe the current state of occupational stress of doctors and nurses at XiengKhoang province hospital, Laos, in 2020. Method: Cross-sectional studies. Result: According to Karasek model, the research participants with the most active jobs accounted for the highest proportion with $51,6 \%$, followed by the group with comfortable work with $26,7 \%$, the group feeling stressful work (love demand for psychology was high and decision-making power) was $14,3 \%$ and the group of research respondents who have to do passive jobs accounts for the lowest rate of $7,5 \%$. Conclusion: The rate of occupational stress among health workers is $14.3 \%$. With the above stress ratio, it is essential at this time that the hospital leaders need to have appropriate interventions to contribute to improving the mental health of medical staff.

Keywords: Occupational stress, JCQ-V

${ }^{1}$ Viện Đào tạo YHDP \& YTCC, Đại học Y Hà Nội

Chịu trách nhiệm chính: Oulyna Phannavong

Email: Pnvhouak@gmail.com

Ngày nhận bài: 23.2.2021

Ngày phản biên khoa hoc: 2.4.2021

Ngày duyệt bài: 14.4 .2021

\section{Oulyna Phannavong ${ }^{1}$, Lê Thị Thanh Xuân¹}

\section{I. ĐĂT VẤN ĐỀ}

Căng thẳng hay stress nghề nghiệp là các phản ứng có hại về tâm sinh lý xảy ra khi yêu câuu về công việc không phù hợp với năng lực, nguồn lực hoặc nhu cầu của người lao động [1]. Stress nghề nghiệp có thể dẫn tới tình trạng suy giảm sức khỏe, thậm trí gây nên thương tích hay tai nạn lao động. Mọi ngành nghề, mọi lứa tuổi và giới tính đều tiềm ẩn những nguy cơ stress trong công việc, tuy nhiên có những ngành nghề có áp lực cao dễ làm cho người lao động stress, trong đó có nghề Y.

Theo nghiên cứu của Shams và El-Masry (2013), tỉ lệ căng thẳng nghề nghiệp trên đối tượng nhân viên y tế (NVYT) chuyên ngành gây mể hồi sức là $69,4 \%$ [2]. Tình trạng quá tải và việc phải mang trọng trách lớn với các vấn đề liên quan đến sinh tử của người bệnh trong quá trình làm việc là những nguyên nhân căn bản dẫn đến căng thẳng trong công việc của NVYT, đặc biệt là những bác sỹ phải trực tiếp đưa ra quyết định [3]. Tại Lào hiện nay việc nghiên cứu tình trạng căng thẳng nghề nghiệp của NVYT còn hạn chế. Do đó chúng tôi tiển hành thực hiện nghiên cứu với mục tiêu "Mô tả thực trạng căng thẳng nghề nghiệp của bác sĩ và điều dưỡng tại Bệnh viện tỉnh Xiêng-Khoảng, Lào, năm 2020".

\section{II. ĐỐI TƯỢNG VÀ PHƯƠNG PHÁP NGHIÊN CỨU}

\section{1. Đối tượng nghiên cứu:}

- NVYT đang làm việc tại bệnh viện tỉnh Xiêng-Khoảng, Lào.

- Tiêu chuẩn lứa chọn: NVYT gồm các bác sĩ, điều đưỡng đang làm việc tại các khoa lâm sàng và khoa cận lâm sàng, có hợp đồng lao động từ 1 năm trở lên tại thời điểm lấy số liệu nghiên cứu và đồng ý tham gia nghiên cứu.

- Tiêu chuẩn loại trừ: NVYT thuộc các khoa chức năng, vắng mặt tại thời điểm thu thập số liệu.

\subsection{Phương pháp nghiên cứu}

2.2.1. Thiết kế nghiên cứu: Nghiên cứu mô tả cắt ngang 
2.2.2. Cỡ mẫu và chọn mẫu Chọn toàn bộ các bác sĩ và điều dưỡng tại các khoa phòng lâm sàng, cận lâm sàng của Bệnh viện tỉnh Xiêng Khoảng, Lào trong khoảng thời gian nghiên cứu thỏa mãn tiêu chuẩn lựa chọn và tiêu chuẩn loại trừ. Thực tế đã phỏng vấn được 161 bác sĩ, điều dưỡng tại các khoa lâm sàng trong tổng số 198 NVYT của các khoa lâm sàng.

2.2.4. Thời gian và địa điểm nghiên cứu

- Thời gian nghiên cứu: Từ tháng 04 năm 2020 đến tháng 05 năm 2021 trong đó thời gian thu thập số liệu tại thực địa là từ tháng 10 đến tháng 12 năm 2020.

- Địa điểm nghiên cứu: Bệnh viện XiêngKhoảng, Cộng hòa dân chủ nhân dân Lào.

\subsubsection{Công cụ và phương pháp thu thập} số liệu

- Công cư thu thập số liệu: sử dụng bộ câu hỏi JCQ-V để đánh giá tình trang căng thẳng nghề nghiệp của NLĐ theo mồ hình Karasek. Gồm 22 câu hỏi và đánh giá trên 3 khía cạnh: áp lực tâm lý, quyền quyết định và sự ủng hộ trong công việc.

- Phương pháp thu thập số liệu: số liệu được thu thập theo phương pháp tự điền vào phiếu câu hỏi dưới sự hướng dẫn và giám sát của điều tra viên.

2.3. Xử lý số liệu: Số liệu được nhập, xử lý và phân tích bằng phần mềm Excel 2016 và MedCalc để xác định tỷ lệ căng thẳng nghề nghiệp và một số yếu tố liên quan đến tình trạng căng thẳng.

2.4. Đạo đức nghiên cứu. Nghiên cứu chỉ được thực hiện sau khi được hội đồng chấm đề cương của Trường Đại học Y Hà Nội chấp thuận thông qua vào tháng 07 năm 2020. Mọi thông tin cá nhân của đối tượng đều được giữ bí mật. Toàn bộ thông tin thu thập trung thực, vì mục đích nghiên cứu, góp phần chẩn đoán, điều trị, vì lợi ích sức khỏe bệnh nhân, hoàn toàn không phục vụ cho mục đích nào khác.

\section{KẾT QUẢ NGHIÊN CỨU}

Bảng 1: Đặc điểm cá nhân của đối tượng nghiên cứu

\begin{tabular}{|c|c|c|c|}
\hline \multicolumn{2}{|c|}{ Đặc điểm cá nhân } & Số lượng & Tỷ lệ \\
\hline \multirow{2}{*}{$\begin{array}{l}\text { Giới } \\
\text { tính }\end{array}$} & Nam & 31 & 19,3 \\
\hline & Nữ & 130 & 80,7 \\
\hline \multirow{3}{*}{$\begin{array}{l}\text { Nhóm } \\
\text { tuổi }\end{array}$} & $<40$ tuối & 115 & 71,4 \\
\hline & $\geq 40$ tuối & 46 & 28,6 \\
\hline & Tuổi trung bình & \multicolumn{2}{|c|}{$\begin{array}{c}37,50 \pm 7,54 \\
(\operatorname{Min}=27 ; \operatorname{Max}=60)\end{array}$} \\
\hline \multirow{2}{*}{$\begin{array}{l}\text { Tôn } \\
\text { giáo }\end{array}$} & Phật giáo & 137 & 85,1 \\
\hline & $\mathrm{Ma}$ & 24 & 14,9 \\
\hline \multirow{3}{*}{$\begin{array}{c}\text { Tình } \\
\text { trạng } \\
\text { hôn } \\
\text { nhân }\end{array}$} & Độc thân & 9 & 5,6 \\
\hline & Đã kết hôn & 149 & 92,5 \\
\hline & $\begin{array}{l}\text { Ly hôn/Ly } \\
\text { thân/Góa }\end{array}$ & 3 & 1,9 \\
\hline \multirow{4}{*}{$\begin{array}{l}\text { Trình } \\
\text { độ học } \\
\text { vấn }\end{array}$} & Trung học cơ sở & 1 & 0,6 \\
\hline & $\begin{array}{l}\text { Trung học phố } \\
\text { thông }\end{array}$ & 22 & 13,7 \\
\hline & $\begin{array}{l}\text { Trung cấp/Cao } \\
\text { đắng/Đại học }\end{array}$ & 114 & 70,8 \\
\hline & Sau đại học & 24 & 14,9 \\
\hline & Tống & 161 & 100,0 \\
\hline
\end{tabular}

Trong 161 đối tượng nghiên cứu, số nhân viên nữ gấp khoảng 4 lần số nam (130 nữ so với 31 nam). Tuổi trung bình của đối tượng nghiên cứu là 37,5 tuổi, thấp nhất là 27 tuổi, cao nhất là 60 tuổi. Nhóm tuổi của đối tượng nghiên cứu chủ yễu là dưới 40 tuổi $(71,4 \%)$. Về tôn giáo, tất cả các đối tượng đều theo tôn giáo, trong đó Phật giáo chiếm tỉ lệ lớn nhất $(85,1 \%)$. Về tình trạng hôn nhân, phần lớn đối tượng đã kết hôn, chiếm $92,5 \%$. Về trình độ học vẩn, phần lớn đối tượng có trình độ trung cấp, cao đẳng hoặc đại học $(70,8 \%)$. Có $14,9 \%$ đối tượng có trình độ sau đại học.

Bảng 2: Quyền quyêt định của bác sĩ và điều dưởing trong công việc

\begin{tabular}{|c|c|c|c|c|c|c|c|}
\hline \multirow{2}{*}{ Quyên quyết định } & \multicolumn{2}{|c|}{ Bác sĩ } & \multicolumn{2}{|c|}{ Điêuu dưỡng } & \multicolumn{2}{|c|}{ Tống } & \multirow[b]{2}{*}{$\mathbf{p}$} \\
\hline & $n$ & $\%$ & $n$ & $\%$ & n & $\%$ & \\
\hline Cao & 40 & 88,9 & 98 & 84,5 & 138 & 85,7 & \\
\hline Thấp & 5 & 11,1 & 18 & 15,5 & 23 & 14,3 & 0,48 \\
\hline Tống & 45 & 100,0 & 116 & 100,0 & 161 & 100,0 & \\
\hline
\end{tabular}

Về quyền quyết định (tự đưa ra quyết định, được sáng tạo trong công việc, nâng cao kỹ năng), $88,9 \%$ nhóm bác sĩ có quyền quyết định cao trong công việc, tỉ lệ này ở nhóm điều dưỡng là $84,5 \%$. Sự khác biệt về tỷ lệ này giữa bác sĩ và điêu dưỡng chưa có ý nghĩa thống kê với $p<0,05$.

Bảng 3: Thực trạng về yêu cầu tâm lý trong công việc của bác sĩ và điều dưỡng

\begin{tabular}{|c|c|c|c|c|c|c|c|}
\hline \multirow{2}{*}{$\begin{array}{l}\text { Yêu câu tâm lý } \\
\text { trong công việc }\end{array}$} & \multicolumn{2}{|c|}{ Bác sĩ } & \multicolumn{2}{|c|}{ Điều dưỡng } & \multicolumn{2}{|c|}{ Tống } & \multirow[b]{2}{*}{$\mathbf{P}$} \\
\hline & $\mathbf{N}$ & $\%$ & $n$ & $\%$ & $n$ & $\%$ & \\
\hline Cao & 33 & 73,3 & 73 & 62,9 & 106 & 65,8 & \\
\hline Thấp & 12 & 26,7 & 43 & 37,1 & 55 & 34,2 & 0,21 \\
\hline Tống & 45 & 100,0 & 116 & 100,0 & 161 & 100,0 & \\
\hline
\end{tabular}


Về yêu cầu tâm lý trong công việc, 73,3\% nhóm bác sĩ thãy các yêu cầu tâm lý mà công việc của mình đặt ra là cao (yêu cầu làm việc nhanh, khối lượng công việc nhiều), cao hơn tỉ lệ này ở nhóm điều dưỡng là $62,9 \%$. Tuy nhiên sự khác biệt về tỷ lệ này giữa bác sĩ và điêu dưỡng chưa có ý nghĩa thống kê với $p<0,05$.

Bảng 4: Thức trạng về sự hỗ trợ từ người hướng dẫn và đồng nghiệp trong công việc của bác sĩ và đ̛iều đưỡng

\begin{tabular}{|c|c|c|c|c|c|c|c|}
\hline \multirow{2}{*}{ Sự hỗ trợ } & \multicolumn{2}{|c|}{ Bác sĩ } & \multicolumn{2}{|c|}{ Điêuu dưỡng } & \multicolumn{2}{|c|}{ Tống } & \multirow{2}{*}{$\mathbf{P}$} \\
\hline & $n$ & $\%$ & $n$ & $\%$ & $\mathbf{N}$ & $\%$ & \\
\hline Cao & 45 & 100,0 & 111 & 95,7 & 156 & 96,9 & \\
\hline Thấp & 0 & 0,0 & 5 & 4,3 & 5 & 3,1 & 0,16 \\
\hline Tống & 45 & 100,0 & 116 & 100,0 & 161 & 100,0 & \\
\hline
\end{tabular}

Về sự hổ trợ từ người hướng dần và đồng nghiệp, $100 \%$ nhóm bác sĩ có sự hỗ trợ cao, còn ở nhóm điều dưỡng là $95,7 \%$. Sự khác biệt giữa hai nhóm về tỷ lệ này chưa có ý nghĩa thống kê với $p<0,05$.

Tình trạng căng thẳng công việc theo mô hình Karasek

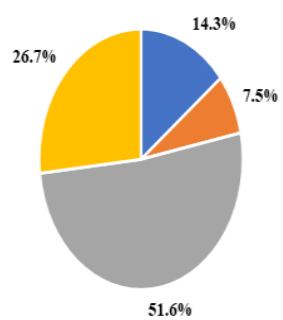

Công việc áp lục caa

" Công việc thụ động

Công việc chư động

" Công việc thoải mái

Biểu đồ 1: Tình trạng căng thẳng trong công viêc theo mô hinh Karasek

Dựa vào thang đo $J C Q$, phân loại được 4 tình trạng căng thẳng công việc ở 161 đối tượng tham gia, bao gồm: công việc áp lực cao (ngưỡng xác định có căng thẳng nghề nghiệp), công việc thụ động, công việc chủ động, cồng việc thoải mái. Trong đó tỉ lệ có căng thẳng nghề nghiệp chiếm $14,3 \%$, đa phần đối tượng có tình trạng công việc chủ động (51,6\%).

\section{BÀN LUÂN}

Sau khi tiến hành điều tra 161 đối tượng bằng bộ công cụ có sử dụng thang đo JCQ, dựa trên mô hình căng thẳng nghề nghiệp của Karasek bằng cách cộng tổng điểm của từng thang đo trong 22 câu hỏi của bộ câu hỏi, chúng tôi đã phân loại được 4 tình trạng căng thẳng công việc bao gồm: công việc áp lực cao (ngưỡng xác định có căng thẳng nghề nghiệp), công việc thụ động, công việc chủ động, công việc thoải mái. Trong đó tỉ lệ có căng thẳng nghề nghiệp chiếm 14,3\% (áp lực tâm lý cao và quyền quyết định thấp), đa phần đối tượng có tình trạng cồng việc chủ động (áp lực tâm lý cao, quyền quyết định cao, chiếm $51,6 \%$ ), công việc thoải mái (quyền quyết định cao, áp lực tâm lý thấp, $26,7 \%$ ) và $7,5 \%$ là công việc thụ động (áp lực tâm lý thấp, quyền quyết định thấp). Điều này có thể được lí giải do đặc thù của ngành, đòi hỏi mức độ chủ động cao, có tính quyết định cao về chuyên môn trong các hoạt động nghề nghiệp của NVYT, đồng thời công việc ít nhàm chán và đơn điệu hơn nên công việc cũng sẽ chủ động và thoải mái hơn. So sánh với kết quả nghiển cứu khác, có đến $60,2 \%$ đối tượng được làm công việc chủ động; $31,6 \%$ đối tượng được làm công việc thoải mái; $6,4 \%$ đối tượng cảm nhận là công việc áp lực cao và chỉ 1,8\% cảm nhận công việc thụ động [4]. Sự khác biệt là có ý nghĩa thống kê, có thể giải thích là do đặc trưng vùng miên, quốc gia.

Như vậy, kết quả trong nghiên cứu cho thấy tỉ lệ có cằng thẳng nghề nghiệp là $14,3 \%$, tỉ lệ này cao hơn so với nghiên cứu của Pham Minh Khuê và Hoàng Thị Giang năm 2011 tại Hải Phòng cũng sử dụng thang đo JCQ (6,39\%)[5]. Tỉ lệ này thấp hơn của Nguyễn Văn Tuyên năm 2015 tại Bệnh viện đa khoa Bình Định (18\%) [6], thấp hơn của Đặng Kim Oanh năm 2017 tại Bệnh viện Đại học Y Hà Nội [7]. Sự khác biệt này có thể là do đối tượng nghiên cứu khác nhau. Nghiên cứu của chúng tôi chọn toàn bộ đối tượng bác sĩ, điều dưỡng lâm sàng trong bệnh viện, trong khi đó nghiên cứu Nguyễn Văn Tuyên, Đặng Kim Oanh chỉ chọn đối tượng là điêu dưỡng mà bỏ qua các đối tượng còn lại, cõ mẫu lớn (483). Do tính chất công việc, điều dưỡng có thể có nguy cơ mắc căng thẳng nghề nghiệp cao hơn các đối tượng khác.

Một lí giải nữa là sự khác nhau về công cụ. Công cụ đo lường căng thẳng của hai tác giả này là DASS21. Công cụ DASS21 sử dụng 7 câu hỏi, tập trung định hướng sàng lọc để tìm ra các trường hợp bị căng thẳng về tâm lý nói chung, có thể liên quan đến công việc hoặc không. Còn công Cụ JCQ là công cụ khai thác sâu vào đặc tính, tính chất công việc (áp lực tâm lý, quyền quyết đinh, sự ủng hộ tại nơi làm việc), sử dụng nhiêu câu hỏi hơn (22 câu) nhằm đánh giá tình 
trạng căng thẳng tại nơi làm việc, mô hình đánh giá đưa ra kết quả về tình trạng căng thẳng sẽ chặt chẽ hơn và có thể đưa ra tỉ lệ thấp hơn. Do đó sự khác biệt về kết quả được mong đợi trước.

\section{KẾT LUÂ̂N}

Tỷ lệ NLĐ làm việc chủ động là $51,6 \%$, tiếp đến là nhóm làm công việc thoải mái chiếm 26,7\%, nhóm cảm nhận công việc của họ căng thẳng (áp lực tâm lý cao và quyên quyết định thấp) chiếm 14,3\%, nhóm NLĐ làm công việc thụ động chiếm tỷ lệ thấp nhất với 7,5\%. Tỷ lệ căng thẳng nghề nghiệp của NVYT tại bệnh viện tỉnh Xiêng - Khoảng, Lào là 14,3\%. Thực tế này đòi hỏi Ban lãnh đạo bệnh viện cân có những biện pháp tiến hành sàng lọc, phát hiện sớm những NVYT có biểu hiện của cẳng thẳng để điều trị sớm và giảm gánh nặng cho gia đình và xã hội.

\section{TÀI LIỆU THAM KHẢO}

1. The National Institute for Occupational Safety and Health (2001). Stress at work.
Center for Diseases Control and Prevention.

2. El-Masry R, Shams T. (2013). Job Stress and Burnout among Academic Career Anaesthesiologists at an Egyptian University Hospital. Sultan Qaboos Univ Med J, 13(2), 287-295.

3. Mrayyan M.T., Hamaideh S.H., Mudallal R., Faouri I.G., Khasawneh N.A (2008). Jordanian nurses' job stressors and social support. Int Nurs Rev, 55(1), 40-47.

4. Lê 'Thi Huế (2018). Căng thẳng nghề nghiêp ở Nhân viên y tế tại Bệnh viện Phong - Da Liễu Trung ương, Quy hòa năm 2018, Trường Đại học Y Hà Nội.

5. Phạm Tuấn Việt, Phạm Minh Khuê, Phạm Văn Manh và cộng sự (2016). Môt số yếu tố liên quạn đến trầm cảm trên công nhần một công ty xi măng tại Hải Phòng. Tạp chí Y học dự phòng, 14(187), 60 .

6. Nguyễn Văn Tuyên (2015). Thực trạng và một số yếu tố liên quan đến căng thẳng của Điều dưỡng viên lâm sàng Bệnh viện đa khoa tỉnh Bình Đinh. Hà Nôi, Đai hoc Y tế Công Cộng.

7. Đặng Kim Oanh (2017). Thực trạng stress nghề nghiếp ở nhân viên điểu dưỡng tai Bênh viện Đạ học Y Hà Nội, Trường Đại học Y Hà Nội.

\section{ĐĂC ĐIỂM DİCH TỄ VÀ CÁC TÁC NHÂN GÂY NGộ ĐộC CẤP ở TRẺ EM TẠI TRUNG TÂM CHỐNG ĐộC BỆNH VIỂN BẠCH MAI}

\section{TÓM TẮT}

Mục tiêu: Mô tả đặc điểm dịch tễ và tác nhân thường gây ngộ độc cấp ở trẻ em tại Trung tâm chống độc bệnh viện Bạch Mai. Đối tượng và phương pháp: nghiên cứu cắt ngang trên 200 bệnh nhân ngộ độc cấp dưới 18 tuổi điều trị tại Trung tẩm chống độc bểnh viên Bach Mai tữ 7/2014 đến 6/2015. Kết quả:

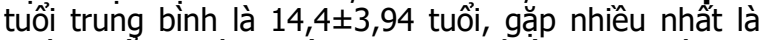
nhóm tuối vị thành niên $(63,5 \%)$. Tî lể nam/nữ là 1,1 . Ngộ độc do không cố ý là 52,5\% (chủ yếu do tai nạn, ngộ đổc thực phẩm); Ngộ độc do cố ý là $47 \%$ (chủ yếu tự tử), bị đâu độc $0,5 \%$. Ngộ độc do cố ý ở trẻ nữ nhiêu hơn nam $(p<0,05)$. Đường ngộ độc chủ yếu là qua đường tiêu hóa (71\%); đến viện sớm trong vòng 6 giờ sau khi bị ngộ độc (63,5\%). Tác nhân chính gây ngộ độc cấp là: hóa chất $(40 \%$, chủ yếu là hóa chất bảo vể thực vật); động vật cắn $(27 \%)$; thực phâmm $(16,5 \%)$; thuốc $(12,5 \%)$; chất gây nghiện (4\%). Kết luận: Hoàn cảnh và các tác nhân gây ngộ độc cấp ở trẻ em rất đa dang và phức tap. Cẩn tăng cường các biện pháp tuyên truyên, giáo dục về nguy cớ, tác

\footnotetext{
${ }^{1}$ Trung Tâm Chông Độc- Bệnh viện Bạch Mai

2Trung tâm Cấp cứu A9 - Bệnh viện Bạch Mai Chịu trách nhiệm chính: Đặng Thị Xuân

Email: xuandangthi17@gmail.com

Ngày nhận bài: 18.2.2021

Ngày phản biện khoa học: 29.3.2021

Ngày duyệt bài: 7.4.2021
}

Đặng Thị Xuân ${ }^{1}$, Đỗ Ngọc Sơn²

nhân và cách phòng tránh ngộ độc ở trẻ em.

Tư khóa: ngộ độc cấp, trẻ em, trung tâm chống độc

\section{SUMMARY}

EPIDEMIOLOGICAL CHARACTERISTICS AND COMMON CAUSES OF ACUTE POISONING IN CHILDREN AT THE POISON CONTROL CENTER BACH MAI HOSPITAL

Objectives: to describe the epidemiological characteristics and the common causes of acute poisoning in children at the Poison Control Center, Bach Mai Hospital. Methods: A cross-sectional study on 200 patients $<18$ years old diagnosed with acute poisoning at the Poison Control Center, Bach Mai hospital from July 2014 to June 2015. Results: The mean age was $14.4 \pm 3.94$ years, most commonly the adolescent group (63.5\%). The male/female ratio was 1.1. The rate of unintentional poisoning was $52.5 \%$ (mainly accident, food poisoning). The rate of poisoning intentionally was $47 \%$ (mainly suicide), poisoned accounts for $0.5 \%$. The rate of intentional poisoning in female were statistically higher than those in male $(p<0.05)$. Poisoning were mainly from the gastrointestinal tract $(71 \%)$. Most of the pediatric patients were admitted to the hospital early, within 6 hours after being poisoned, accounting for $63.5 \%$. The main causes of common acute poisoning are: chemicals ( $40 \%$ - of which are mainly plant protection chemicals); animal bites (27\%); food (16.5\%); medicine (12.5\%); addictive substances (4\%). 